\title{
The impact of HLA-matching on reduced intensity conditioning regimen unrelated donor allogeneic stem cell transplantation for acute myeloid leukemia in patients above 50 years - a report from the EBMT acute leukemia working party
}

Marie T. Rubio ${ }^{1,2,3,4^{*}}$, Bipin N. Savani ${ }^{4,5^{*}}$, Myriam Labopin ${ }^{4,6,7,8,9}$, Emmanuelle Polge ${ }^{4,6,7,8,9}$, Dietger Niederwieser ${ }^{10}$, Arnold Ganser ${ }^{11}$, Rainer Schwerdtfeger ${ }^{12}$, Gerhard Ehninger ${ }^{13}$, Jürgen Finke ${ }^{14}$, Arnold Renate ${ }^{15}$, Charles Craddock ${ }^{16}$, Nicolaus Kröger ${ }^{17}$, Michael Hallek ${ }^{18}$, Pavel Jindra ${ }^{19}$, Mohamad Mohty ${ }^{4,6,7,8,9}$ and Arnon Nagler ${ }^{4,20}$

\begin{abstract}
Background: Data comparing fully matched and mismatched-unrelated-donor ( $M$ - and mM-URD) allogeneic hematopoietic stem cell transplant (allo-SCT) following reduced intensity conditioning regimens for acute myeloid leukemia are limited.

Methods: We retrospectively compared the outcome of 3398 patients above the age of 50 years who underwent 10/10 M-URD ( $n=2567), 9 / 10(n=723)$, or 8/10 ( $n=108)$ mM-URD allo-SCT for acute myeloid leukemia after reduced intensity conditioning regimen between 2000 and 2013. The Kaplan-Meier estimator, the cumulative incidence function, and Cox proportional hazards regression models were used where appropriate.

Results: HLA matching had no impact on engraftment $(p=0.31)$. In univariate analysis, in comparison to 10/10 M-URD, mM-URD was associated with higher incidence of grade II-IV acute graft-versus-host disease (GVHD) $(p=0.0002)$, similar rates of chronic GVHD ( $p=0.138$ ) but increased incidence of its extensive form ( $p=0.047)$. Compared to 10/10 M-URD, patients transplanted in the first complete remission (CR1) with a 9 or an 8/10 mM-URD had decreased 2-year leukemia free (LFS) ( $p=0.005)$ and overall survivals (OS) $(56.7,46.1$, and $50.2 \%$, respectively, $p=0.005)$, while outcomes were comparable between all groups for patients transplanted beyond CR1. In multivariate analysis, 9/10 versus 10/10 URD was associated with higher non-relapse mortality (HR 1.34, $p=0.001$ ), similar risk of relapse and chronic GVHD and inferior LFS (HR 1.25, $p=0.0001)$, and OS (HR 1.27, $p=0.0001)$. There was no difference in adjusted transplant outcomes between $9 / 10$ and 8/10 mM-URD.

(Continued on next page)
\end{abstract}

*Correspondence: mt_rubio@hotmail.com; Bipin.Savani@Vanderbilt.Edu

Marie T. Rubio and Bipin N. Savani are joint first co-authors.

${ }^{1}$ Department of Hematology, Hôpital Brabois, CHRU Nancy,

Vandœuvre-lès-Nancy, France

${ }^{4}$ Acute Leukemia Working Party of EBMT, Paris, France

Full list of author information is available at the end of the article 
(Continued from previous page)

Conclusions: Reduced intensity conditioned allo-SCT with a 10/10 M-URD remains the preferable option for AML patients above the age of 50 years. The use of a 9/10 or an 8/10 mM-URD in patients not having a fully matched donor represents an alternative therapeutic option that should be compared to other alternative donor transplant strategies.

Keywords: Allogeneic stem cell transplantation, Unrelated donor, Older patients, HLA matching, Acute leukemia, Toxicity, Anti-leukemic effect

\section{Background}

The development of reduced intensity conditioning (RIC) regimens has allowed to offer allogeneic hematopoietic stem cell transplantation (allo-SCT) to adults above the age of 50 years and patients with comorbidities [1-8]. In acute myeloid leukemia (AML), allo-SCT performed with RIC regimen improves the leukemia-free survival (LFS) of older adults in comparison to standard chemotherapy [9-11] and reduces nonrelapse mortality (NRM) in comparison to myeloablative conditioning (MAC) [11, 12]. RIC allo-SCT is therefore the treatment of choice for intermediate- and high-risk AML patients above 50 years having an HLA compatible donor [9-11, 13].

As only about one third of the patients that are in need of allo-SCT have a matched-related donor and donor registries have increased the probability to find a suitable unrelated donor (URD), increasing numbers of patients are receiving matched (M-URD) and mismatched unrelated donor (mM-URD) allo-SCT [14, 15]. The outcomes of M-URD and mM-URD transplant have significantly improved in the last decade [14, 16, 17]. Although the MRC AML15 Trial has recently reported improved overall survival with matched related donors (MRD) compared to M-URD due to reduced NRM [11], several studies have shown similar outcomes of MRD in comparison to M-URD or mM-URD after RIC allo-SCT for AML $[6,18-20]$. Among M-URD, comparative data between M-URD and mM-URD are limited, in particular in the context of RIC allo-SCT for older adults with AML.

Acute leukemias in the elderly population are characterized as more aggressive diseases due to selection of more primitive clones with higher prevalence of complex karyotype and presence of multidrug resistance [21, 22]. Disease control after RIC allo-SCT mainly relies on the anti-leukemic effect of allogeneic NK and T cells $[23,24]$. Since HLA mismatching might improve graft-versus-leukemia effect in high-risk acute leukemias [25], one might hypothesize that HLA-mismatched RIC-allo SCT for AML in patients above the age of 50 years could offset the higher risk of NRM by reducing the need of myeloablative doses of chemotherapy aiming in reducing the risk of relapse. In the present study, we analyzed the outcome of 3398 adult patients above the age of 50 years who underwent matched or mismatched URD allo-SCT with RIC regimen for AML.

\section{Methods}

Study design and data collection

This is a retrospective multicenter analysis using the data set of the acute leukemia working party (ALWP) of the European Society of Blood and Marrow Transplantation (EBMT) group registry. The EBMT is a voluntary working group of more than 500 transplant centers that are required to report all consecutive stem cell transplantations and follow-ups once a year. Audits are routinely performed to determine the accuracy of the data. The study was planned and approved by the ALWP of the EBMT. In addition, the study protocol was approved by the institutional review board at each site and complied with country-specific regulatory requirements. The study was conducted in accordance with the Declaration of Helsinki and Good Clinical Practice guidelines. Since 1990, patients provide informed consent authorizing the use of their personal information for research purposes. Eligibility criteria for this analysis included patients with AML above 50 years old who underwent a first allo-SCT from an HLA-matched (10/10) or mismatched $(9 / 10$ or 8/10) unrelated donor (mM-URD) following RIC regimen between 2000 and 2013. All donors were HLA matched $(10 / 10)$ or mismatched at one or two loci $(9 / 10$ or $8 / 10)(-\mathrm{A},-\mathrm{B},-\mathrm{C}$, DRB1, $-\mathrm{DQB1})$. HLA typing was determined at all loci by high-resolution techniques. Exclusion criteria were previous allogeneic or cord blood transplantation, ex vivo T cell-depleted stem cell graft. Regimens were classified as RIC based on EBMT criteria [26]. Variables collected included recipient and donor characteristics (age, gender, CMV serostatus, recipient's Karnofsky status at transplant), disease characteristics and status at transplant, year of transplantation and interval from diagnosis to transplantation, transplantrelated factors including conditioning regimen, pretransplant in vivo $\mathrm{T}$ cell depletion, stem cell source (bone marrow (BM) or peripheral blood (PB)), posttransplant graft-versus-host disease (GVHD) prophylaxis, and outcome variables (acute and chronic GVHD, 
relapse, NRM, LFS, OS, and causes of death). Grading of acute GVHD was performed using established criteria [27]. Chronic GVHD was classified as limited or extensive according to published criteria [28]. For the purpose of this study, all necessary data were collected according to the EBMT guidelines, using the EBMT Minimum Essential Data forms. The list of institutions reporting data included in this study is provided in Additional file 1: Table S1.

\section{Statistical analysis}

Primary endpoints of the study were incidences and severity of acute and chronic GVHD, NRM, and disease relapse incidence (RI). Secondary endpoints included engraftment, OS, and LFS. Start time was the date of transplant for all endpoints. LFS was defined as survival without relapse or progression and NRM as death without relapse/progression. Cumulative incidence functions (CIFs) were used to estimate RI and NRM in a competing risk setting, because death and relapse compete with each other. For estimating the cumulative incidence of chronic GVHD, we considered relapse and death to be competing events. The three groups according to level of HLA matching were compared by the chi-square method for qualitative variables, whereas the MannWhitney test was applied for continuous parameters. Univariate comparisons were done using the log-rank test for OS, LFS, and the Gray's test for RI, NRM, and GVHD cumulative incidences. Multivariate analyses were performed using logistic regression for grade II-IV acute GVHD rate and Cox proportional hazards model for all other endpoints. Factors differing in terms of distribution between the three groups and all factors known as potentially risk factors were included in the final model. Factors included in the Cox models included HLA matching, patient age (analyzed by 10-year scale), and Karnofsky status ( $\geq 80 \%$ versus below $80 \%$ ), year of transplantation, time from diagnosis to transplantation (per 6 months), disease status at transplantation, secondary AML versus de novo AML, low-dose TBI-based versus chemotherapy-based RIC regimens, use of in vivo $\mathrm{T}$ cell depletion, female donor to male recipient versus other gender combinations, and CMV risk (high-risk seropositive recipient with seronegative donor versus others combinations). All tests were two sided. The type I error rate was fixed at 0.05 for determination of factors associated with time to event outcomes. Statistical analyses were performed with SPSS 22.0 (IBM Corp., Armonk, NY, USA) and R 3.1.1 software packages (R Development Core Team, Vienna, Austria).

\section{Results}

Patient, disease, and transplant characteristics

Details of patients, disease, and transplant characteristics are summarized in Table 1 . Three thousand three hundred ninety-eight patients with AML were included in the study. Two thousand five hundred sixty-seven patients $(75.5 \%)$ received a HLA $10 / 10$ fully matched, while $723(21.3 \%)$ received a 9/10 and 108 (3.2 \%) received an $8 / 10$ mismatched unrelated donor (mM-URD) allo-SCT between 2000 and 2013. All patients were older than 50 years and median age was comparable between the three groups (60 to 61 years with ranges between 50 and 78 years) (Table 1). Patients receiving an HLA 8/10 mM-URD had been transplanted more lately than the two other groups (median year of transplantation 2009 versus 2011, $p=0.001$ ) and had a longer follow up of surviving patients (median 34 versus 24 months, $p=0.042$ ). Interval from diagnosis to transplantation was shorter in the HLA $10 / 10$ in comparison to the $9 / 10$ and $8 / 10 \mathrm{mM}$-URD groups (212 versus 250 and 295 days, respectively, $p=$ 0.0001). Patients in the mM-URD groups had been more frequently transplanted with a female donor $\left(p<10^{-4}\right)$ and more transplants were performed from female donor to male recipient $(p=0.01)$. Secondary AML was more frequent in the $8 / 10 \mathrm{mM}$-URD group (44 versus $<30 \%, p=0.001)$. The proportions of poor cytogenetics were equally distributed between the three groups although cytogenetic analysis was missing in 52 to $55 \%$, of the patients. Significantly higher numbers of patients were transplanted in CR1 in the 10/10 URD in comparison to the $9 / 10$ and $8 / 10 \mathrm{mM}$-URD groups (55 versus 46.1 and $44.4 \%$, respectively, $p=0.0002$ ). Peripheral blood represented the major source of stem cells in all groups. TBI-based RIC was less frequently used in the $8 / 10$ HLA mM-URD group $(p=0.02)$. Patients in the mM-URD groups had received more frequently in vivo $\mathrm{T}$ cell depletion in comparison to $10 / 10$ matched URD SCT $(86 \%$ in $8 / 10,83.1 \%$ in $9 / 10$ versus $73.5 \%$ in $10 / 10$ groups, $p<10^{-4}$ ). There was higher proportions of patients with high CMV reactivation risk (negative donor with positive recipient CMV serologies) in the 9/10 group in comparison to the others $(p=0.029)$. The choice of conditioning and GVHD prophylaxis was dependent on centers' protocols and strategies of transplantation.

\section{Engraftment and GVHD}

Engraftment and incidences of acute and chronic GVHD are summarized in Table 2 . There was no difference in terms of engraftment between the $10 / 10,9 / 10$, and $8 / 10$ groups (97.3, 96.3, and $97.1 \%$, respectively, $p=0.313$ ). Median time for ANC $>0.5 \times 10^{9} / \mathrm{L}$ was also similar between the three groups $(16,16$, and 15.5 days, respectively, $p=0.538$ ).

In univariate analysis, incidence of day 100 grade II-IV and grade III-IV acute GVHD were significantly higher in $8 / 10$ and 9/10 mM-URD in comparison to HLA 10/10 MURD groups $(34.3,32.8$, and $25.6 \%$ for grade II-IV aGVHD, respectively, $p=0.0002$; and 10.8, 12.9 , and $9.5 \%$ 
Table 1 Patients and disease characteristics

\begin{tabular}{|c|c|c|c|c|}
\hline Patient characteristics & HLA 10/10 & HLA 9/10 & HLA 8/10 & $p$ value \\
\hline Number of patients & 2567 & 723 & 108 & \\
\hline Recipient age at SCT (years, range) & $61(50-78)$ & $61(50-77)$ & $60(50-73)$ & 0.584 \\
\hline \multicolumn{4}{|l|}{ Recipient gender, $n(\%)$} & 0.707 \\
\hline Male & $1386(54 \%)$ & $387(53.7 \%)$ & $62(58 \%)$ & \\
\hline Female & $1177(46 \%)$ & $334(46.3 \%)$ & $45(42 \%)$ & \\
\hline Year of SCT (median), year (\%) & $2011(00-13)$ & $2011(02-13)$ & $2009(00-13)$ & 0.001 \\
\hline Interval from diagnosis to SCT (days) & 212 & 250 & 295 & 0.0001 \\
\hline Median follow-up (months, range) & $24(1-150)$ & $24(1-139)$ & $34(3-117)$ & 0.042 \\
\hline Donor age (years, range) & $33(16-61)$ & $36(20-61)$ & $35(20-55)$ & 0.02 \\
\hline \multicolumn{4}{|l|}{ Donor gender, $n(\%)$} & $<10^{-4}$ \\
\hline Male & 1845 (73\%) & $463(65.2 \%)$ & $69(64.5 \%)$ & \\
\hline Female & $682(27 \%)$ & 247 (34.8 \%) & $38(35.5 \%)$ & \\
\hline Female donor to male recipient, $n(\%)$ & $281(11.1 \%)$ & $106(15 \%)$ & $17(16 \%)$ & 0.01 \\
\hline \multicolumn{4}{|l|}{ Diagnosis, $n(\%)$} & 0.001 \\
\hline De novo AML & 1805 (70.3 \%) & $527(72.9 \%)$ & $60(55.6 \%)$ & \\
\hline Secondary AML & $762(29.7 \%)$ & 196 (27.1 \%) & $48(44.4 \%)$ & \\
\hline \multicolumn{4}{|c|}{ Cytogenetics in de novo AML, $n$ (\% of available data) } & 0.235 \\
\hline Good & $75(9.2 \%)$ & $15(5.9 \%)$ & $2(7.1 \%)$ & \\
\hline Intermediate & $545(67.2 \%)$ & $183(72 \%)$ & $23(82 \%)$ & \\
\hline Poor & $191(23.5 \%)$ & $56(22 \%)$ & $3(10.7 \%)$ & \\
\hline Not available/failed & $994(55 \%)$ & $273(51.8 \%)$ & $32(53.3 \%)$ & \\
\hline \multicolumn{4}{|l|}{ Disease status at SCT, $n(\%)$} & 0.0002 \\
\hline CR1 & $1413(55 \%)$ & $333(46.1 \%)$ & $48(44.4 \%)$ & \\
\hline$\geq C R 2$ & $504(19.7 \%)$ & $171(23.6 \%)$ & $25(23.2 \%)$ & \\
\hline Active disease & $650(25.3 \%)$ & $219(30.3 \%)$ & $35(32.4 \%)$ & \\
\hline \multicolumn{4}{|l|}{ Source of SC, n (\%) } & 0.173 \\
\hline BM & $154(6 \%)$ & $56(7.8 \%)$ & $9(8.3 \%)$ & \\
\hline PB & $2413(94 \%)$ & 667 (92.2 \%) & 99 (91.7 \%) & \\
\hline \multicolumn{4}{|l|}{ Conditioning, n (\%) } & 0.02 \\
\hline Chemo alone & 1836 (71.5 \%) & 550 (76.1 \%) & $84(77.8 \%)$ & \\
\hline Low TBI & $731(28.5 \%)$ & $173(23.9 \%)$ & $24(22.2 \%)$ & \\
\hline \multicolumn{4}{|l|}{ In vivo T cell depletion, $n$ (\%) } & $<10^{-4}$ \\
\hline No & $672(26.4 \%)$ & $121(16.9 \%)$ & $15(14.0 \%)$ & \\
\hline ATG & $1460(57.5 \%)$ & $468(65.2 \%)$ & $59(55.1 \%)$ & \\
\hline Campath & 409 (16.1\%) & $129(18.0 \%)$ & $33(30.8 \%)$ & \\
\hline \multicolumn{4}{|l|}{ Post-transplant GVHD prophylaxis } & 0.07 \\
\hline CsA & $504(19.9 \%)$ & $135(18.8 \%)$ & $27(25.5 \%)$ & \\
\hline CsA/FK $506+$ MTX & $517(20.4 \%)$ & 177 (24.7 \%) & $16(15.1 \%)$ & \\
\hline CsA/FK $506+$ MMF & 1353 (53.4 \%) & $353(49.2 \%)$ & $53(50 \%)$ & \\
\hline Other & 160 (6.3\%) & $53(7.4 \%)$ & $10(9.4 \%)$ & \\
\hline Missing & 33 & 5 & 2 & \\
\hline
\end{tabular}


Table 1 Patients and disease characteristics (Continued)

\begin{tabular}{|c|c|c|c|c|}
\hline Karnosky at SCT, $n(\%)$ & & & & 0.47 \\
\hline$\leq 80 \%$ & $173(6.7 \%)$ & $42(5.8 \%)$ & $9(8.4 \%)$ & \\
\hline$>80 \%$ & $2231(86.9 \%)$ & $641(88.7 \%)$ & $91(84.2 \%)$ & \\
\hline Missing & $163(6.4 \%)$ & $40(5.5 \%)$ & $8(7.4 \%)$ & \\
\hline Patient positive CMV serology, $n(\%)$ & $1634(64.9 \%)$ & $492(69.1 \%)$ & $67(63.8 \%)$ & 0.10 \\
\hline CMV risk, $n(\%)$ & & & & 0.029 \\
\hline Low & $695(27.8 \%)$ & $155(21.9 \%)$ & $26(24.8 \%)$ & \\
\hline Intermediate & $1072(42.8 \%)$ & $316(44.7 \%)$ & $47(44.8 \%)$ & \\
\hline High & $734(29.4 \%)$ & $236(33.4 \%)$ & $32(30.5 \%)$ & \\
\hline
\end{tabular}

$A M L$ acute myeloid leukemia, ATG anti-thymocyte globulin, BM bone marrow, $C M V$ cytomegalovirus, $C M V$ risk low = negative recipient and donor serology, high positive recipient and negative donor serology, intermediate all other combinations, $C R$ complete remission, $P B$ peripheral blood, SC stem cells, SCT stem cell transplantation

${ }^{\text {a}}$ For patients alive

for grade III-IV aGVHD, respectively, $p=0.035$ ) (Table 2). Incidences of grade II-IV and grade III-IV aGVHD were lower in patients who received in vivo $\mathrm{T}$ cell depletion compared to those who did not $(23.7$ versus $33 \%, p<10^{-4}$, and 9 versus $14.3 \%, \mathrm{p}<10^{-4}$, respectively). Two-year incidence of all grades chronic GVHD was not significantly different between the three groups: $44.5 \%$ in the HLA $8 / 10$ mM-URD, $35.1 \%$ in the $9 / 10 \mathrm{mM}-\mathrm{URD}$, and $35 \%$ in the HLA 10/10 M-URD groups $(p=0.138)$ (Tables 2 and 3 and Fig. 1a). However, an increased incidence was observed in the HLA $8 / 10$ mM-URD group for patients transplanted above second complete remission $(\geq \mathrm{CR} 2)$
(65.5 versus $34.7 \%$ in HLA $9 / 10$ and $35 \%$ in HLA $10 / 10$ matched mM-URD groups, $p=0.01$ ) (Table 3 ). Incidence of extensive chronic GVHD was also increased in the $8 / 10 \mathrm{mM}$-URD compared to $9 / 10 \mathrm{mM}$-URD and 10/10 M-URD groups (26.1 versus 15.2 and $17.1 \%$, respectively, $p=0.047$ ) (Table 2 and Fig. 1b), in particular in the group of patients transplanted in advanced phase (32.2 versus 18.3 and $13.2 \%$, respectively, $p=0.02$ ) (Table 3 ). Incidences of overall cGVHD and extensive cGVHD were reduced in patients who received an in vivo $\mathrm{T}$ cell depletion in comparison to those who did not (32.9 versus $45 \%, p<0.0001$, and 14.6 versus $26.4 \%, p<0.0001$, respectively) (Table 3). As shown in Table 4, GVHD-

Table 2 Engraftment and GVHD

\begin{tabular}{|c|c|c|c|c|}
\hline & HLA 10/10 & HLA 9/10 & HLA 8/10 & $p$ value \\
\hline Total number of patients & 2567 & 723 & 108 & \\
\hline Engraftment, $n(\%)$ & $2458(97.3 \%)$ & $678(96.3 \%)$ & $101(97.12 \%)$ & 0.313 \\
\hline No engraftment, $n(\%)$ & $67(2.7 \%)$ & $26(3.7 \%)$ & $3(2.9 \%)$ & \\
\hline Missing, $n$ & 42 & 19 & 5 & \\
\hline Median time ANC >0.5 G/L (days, range) & $16(0-103)$ & $16(1-165)$ & $15.5(1-33)$ & 0.538 \\
\hline \multicolumn{5}{|l|}{ Acute GVHD, } \\
\hline Grade $0-I, n(\%)$ & $1826(74.4 \%)$ & $469(67.2 \%)$ & $67(65.7 \%)$ & 0.0002 \\
\hline Grades II-IV, $n(\%)$ & $629(25.6 \%)$ & $229(32.8 \%)$ & $35(34.3 \%)$ & \\
\hline Grades III-IV, n (\%) & $234(9.5 \%)$ & $90(12.9 \%)$ & $11(10.8 \%)$ & 0.035 \\
\hline Missing, $n$ & 75 & 21 & 3 & \\
\hline \multicolumn{5}{|l|}{ Chronic GVHDa } \\
\hline All grades & $35.0 \%[32.9-37.2]$ & $35.1 \%[31.2-39]$ & $44.4 \%[33.6-54.6]$ & 0.138 \\
\hline Extensive & $17.1 \%[15.4-18.9]$ & $15.2 \%[12.3-18.5]$ & $26.1 \%$ [16.8-36.4] & 0.047 \\
\hline Limited, $n$ & 369 & 109 & 14 & \\
\hline Extensive, $n$ & 324 & 80 & 21 & \\
\hline Missing, $n$ & 38 & 18 & 5 & \\
\hline
\end{tabular}


Table 3 Comparison of 2-year outcomes according to donor HLA matching, disease status, and use of in vivo T cell depletion

\begin{tabular}{|c|c|c|c|c|c|c|c|}
\hline $\begin{array}{l}\text { Disease } \\
\text { status }\end{array}$ & $\begin{array}{l}\text { Patients group } \\
\text { and } p \text { value }\end{array}$ & $\mathrm{Rl}$ & NRM & LFS & OS & cGVHD & $\begin{array}{l}\text { Extensive } \\
\text { cGVHD }\end{array}$ \\
\hline \multirow[t]{4}{*}{ All } & $10 / 10$ & $30.1 \%$ [28.2-32.1] & $24.2 \%[16.4-32.9]$ & $45.6 \%[43.5-47.7]$ & $50.6 \%[48.5-52.8]$ & $35.0 \%[32.9-37.2]$ & $17.1 \%[15.4-18.9]$ \\
\hline & $9 / 10$ & $32.5 \%$ [28.9-36.3] & $31.6 \%[23-40.5]$ & $35.8 \%$ [32-39.7] & $41.3 \%$ [37.3-45.3] & $35.1 \%$ [31.2-39] & $15.2 \%$ [12.3-18.5] \\
\hline & $8 / 10$ & $24.2 \%$ [16.4-32.9] & $35.5 \%[26.6-44.4]$ & $40.3 \%$ [30.6-50] & $43.5 \%[33.6-53.3]$ & $44.4 \%[33.6-54.6]$ & $26.1 \%$ [16.8-36.4] \\
\hline & $p$ value & 0.152 & 0.002 & 0.0001 & 0.0001 & 0.138 & 0.047 \\
\hline \multirow[t]{4}{*}{ CR1 } & $10 / 10$ & $24.8 \%$ [22.4-27.3] & $22.5 \%[11.6-35.7]$ & $52.6 \%[49.7-55.5]$ & $56.7 \%$ [53.8-59.6] & $37.6 \%[34.7-40.5]$ & $18.1 \%$ [15.8-20.5] \\
\hline & $9 / 10$ & $31.6 \%$ [26.3-37.2] & $26.8 \%[14.8-40.2]$ & $41.6 \%[35.7-47.5]$ & $46.1 \%[40.1-52.2]$ & $35.9 \%$ [30-41.9] & $13 \%$ [9.1-17.7] \\
\hline & $8 / 10$ & $17.7 \%[8.1-30.2]$ & $33.3 \%$ [20.4-46.8] & $49 \%$ [34.3-63.7] & $50.2 \% \%[35.2-65.1]$ & $43.4 \%$ [26.4-59.2] & $22.1 \%$ [9.5-37.9] \\
\hline & $p$ value & 0.010 & 0.136 & 0.005 & 0.005 & 0.641 & 0.107 \\
\hline \multirow[t]{4}{*}{$\geq \mathrm{CR} 2$} & $10 / 10$ & $32.6 \%$ [28.2-37.1] & $24.1 \%[8.7-43.5]$ & $43.3 \%[38.5-48.1]$ & $50.1 \%[45.3-55]$ & $35 \%$ [30.3-39.7] & $13.9 \%$ [10.6-17.7] \\
\hline & $9 / 10$ & $26.3 \%$ [19.5-33.5] & $32.5 \%[14.6-51.8]$ & $41.2 \%[33.3-49.2]$ & $48 \%[40-56.1]$ & $34.7 \%$ [26.8-42.7] & $18.3 \%[12.1-25.6]$ \\
\hline & $8 / 10$ & $22.4 \%[7.7-41.7]$ & $24.6 \%[9.1-44.1]$ & $53 \%[31.3-74.7]$ & $62 \%[40.8-83.3]$ & $65.5 \%$ [39.6-82.4] & $32.2 \%$ [13.8-52.3] \\
\hline & $p$ value & 0.304 & 0.089 & 0.290 & 0.253 & 0.010 & 0.020 \\
\hline \multirow[t]{4}{*}{ Act. dis. } & 10/10 & $39.7 \%$ [35.7-43.7] & $28 \%$ [13.8-44] & $32.3 \%$ [28.4-36.3] & $37.9 \%$ [33.8-42] & $29.4 \%$ [25.5-33.4] & $17.5 \%$ [14-21.5] \\
\hline & $9 / 10$ & $38.4 \%$ [31.6-45.3] & $38 \%$ [22.3-53.6] & $23.6 \%$ [17.4-29.7] & $29.1 \%$ [22.5-35.7] & $33.9 \%$ [27.1-40.8] & $16.1 \%$ [10.7-22.5] \\
\hline & $8 / 10$ & $34.3 \%$ [19-50.2] & $45.7 \%$ [29.7-60.4] & $20 \%$ [6.7-33.3] & $22.9 \%$ [8.9-36.8] & $30 \%$ [14.4-47.4] & $26.1 \%$ [10.1-45.5] \\
\hline & $p$ value & 0.902 & 0.062 & 0.107 & 0.139 & 0.587 & 0.578 \\
\hline In vivo & No & $28.8 \%$ [25.4-32.3] & $27.1 \%$ [23.7-30.7] & $44 \%[40.1-48]$ & $47.7 \%$ [43.7-51.8] & $45 \%$ [40.8-49] & $26.4 \%[22.5-30.4]$ \\
\hline T cell & Yes & $30.7 \%$ [28.8-32.6] & $25.9 \%[22.5-29.4]$ & $43.4 \%[41.3-45.5]$ & $48.8 \%$ [46.7-50.9] & $32.9 \%$ [30.9-34.9] & $14.6 \%$ [13-16.2] \\
\hline Depletion & $p$ value & 0.920 & 0.448 & 0.613 & 0.448 & $1.0483 e-05$ & $1.337 \mathrm{e}-09$ \\
\hline
\end{tabular}

Act. dis. active disease, CGVHD chronic graft-versus-host-disease, CR complete remission, LFS leukemia-free survival, NRM non relapse mortality, OS overall survival, $R /$ relapse incidence

related deaths represented $17.2,20.1$, and $17.3 \%$ of all causes of death in the $8 / 10,9 / 10$, and 10/10 HLA groups, respectively.

Multivariate analyses are shown in Table 5. Factors associated with increased risk of grade II-IV acute GVHD were the use of $9 / 10 \mathrm{mM}-\mathrm{URD}$ in comparison to $10 / 10$ M-URD (HR 1.47, 95 \% CI 1.21-1.79; $p=0.0001$ ), active disease at transplantation (HR 1.34, 95 \% CI 1.1-1.63; $p=0.004$ ) and high $\mathrm{CMV}$ risk (seropositive recipient and seronegative donor) (HR 1.28, 95 \% CI 1.03-1.60;

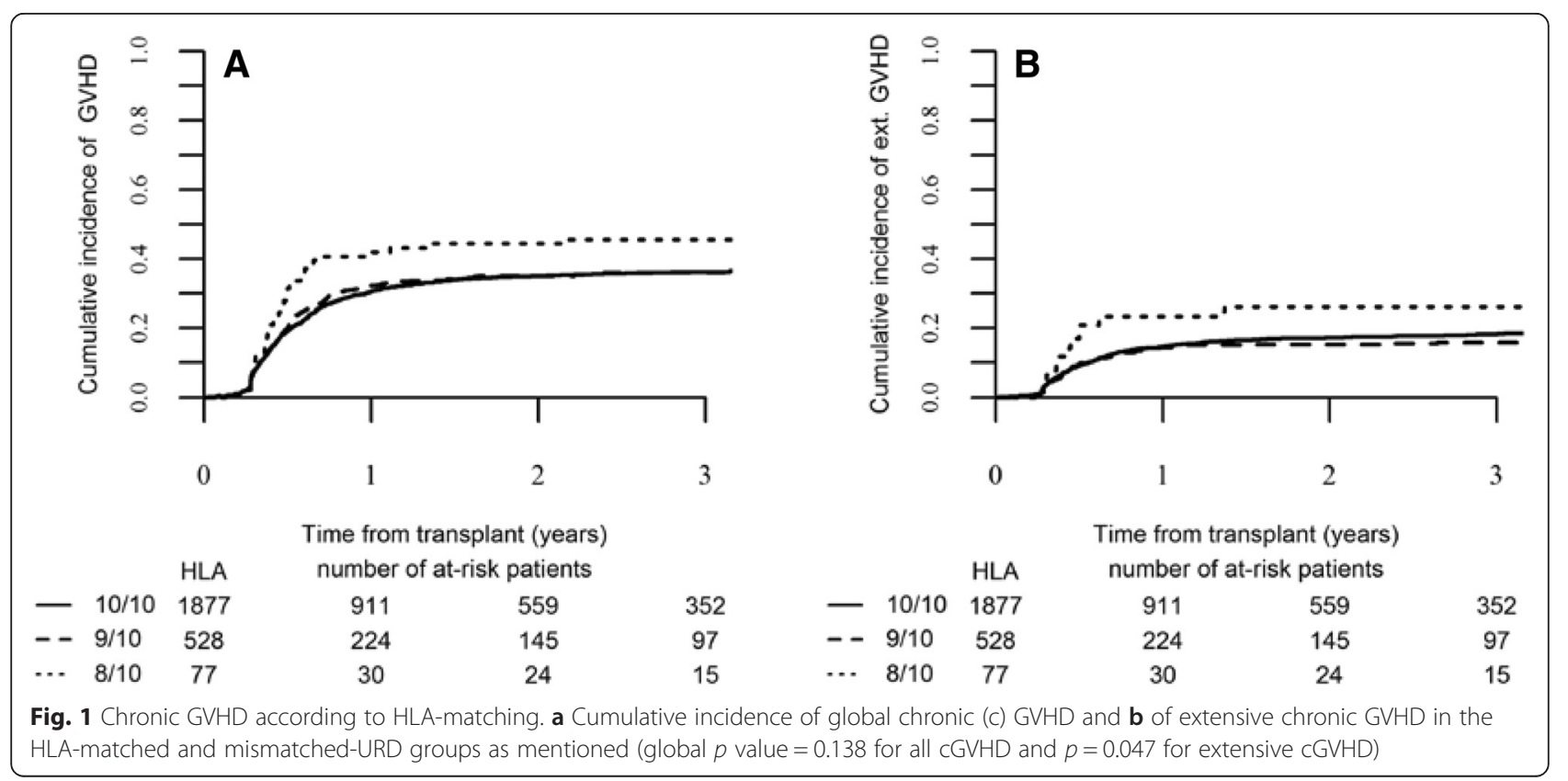


Table 4 Causes of death according to donor HLA matching

\begin{tabular}{llll}
\hline & HLA 10/10 & HLA 9/10 & HLA 8/10 \\
\hline Relapse & $552(47.5 \%)$ & $173(43.4 \%)$ & $21(36.2 \%)$ \\
Infection & $249(21.3 \%)$ & $100(25.1 \%)$ & $21(36.2 \%)$ \\
GVHD & $202(17.3 \%)$ & $80(20.1 \%)$ & $10(17.2 \%)$ \\
Graft failure/rejection & $11(0.9 \%)$ & $1(0.3 \%)$ & 0 \\
Cardiac toxicity & $8(0.7 \%)$ & $4(1 \%)$ & $1(1.7 \%)$ \\
Haemorhage & $14(1.2 \%)$ & $5(1.3 \%)$ & $1(1.7 \%)$ \\
VOD & $12(1 \%)$ & $8(2 \%)$ & 0 \\
Idiopathic pneumonia & $25(2.1 \%)$ & $9(2.3 \%)$ & 0 \\
Second malignancy & $24(2.1 \%)$ & $5(1.3 \%)$ & 0 \\
Other SCT-related & $70(6 \%)$ & $14(3.5 \%)$ & $4(6.9 \%)$
\end{tabular}

GVHD graft-versus-host disease, SCT stem cell transplantation, VOD veno-occlusive disease

$p=0.028$ ), while the use of in vivo $\mathrm{T}$ cell depletion was associated with reduced risk of grade II-IV acute GVHD (HR 0.61, $95 \%$ CI $\left.0.49-0.75 ; p<10^{-4}\right)$. The use of an $8 / 10 \mathrm{mM}$-URD was not associated with an increased incidence of grade II-IV aGVHD in comparison to a 9/10 mM-URD $(p=0.952)$. Chronic GVHD was not significantly different between HLA 10/10 matched and 9/10 mM-URD groups $(p=0.418)$ or between HLA $9 / 10$ and $8 / 10 \mathrm{mM}$-URD groups $(p=0.145)$. The only factor associated with increased risk of chronic GVHD was active disease at allo-SCT (HR 1.22, $95 \%$ CI 1.03-1.45; $p=0.019$ ), while in vivo $\mathrm{T}$ cell depletion was associated with reduced risk of chronic GVHD development (HR 0.72, 95 \% CI $0.61-0.85 ; p=0.0001$ ) (Table 5).

\section{Toxicity and NRM}

Two-year NRM for the entire cohort was $26.1 \%$ (95\% CI, 24.6-27.8). In univariate analysis, 2-year NRM was significantly higher in mM-URD groups (35.5\%, $95 \%$ CI $26.6-$ 44.4 in HLA $8 / 10$ and $31.6 \%, 95 \%$ CI 23-40.5 in HLA 9/ 10 mM-URD groups) in comparison to the HLA 10/10 M-URD group (24.2 \%, $95 \%$ CI 16.4-32.9) $(p=0.001)$ (Table 3). In multivariate analysis, the use of a $9 / 10 \mathrm{mM}$ URD was associated with increased NRM in comparison to HLA 10/10 matched URD (HR 1.34, 95 \% CI 1.13$1.58 ; p=0.001$ ), while there was no difference in NRM between $9 / 10$ and $8 / 10 \mathrm{mM}$-URD $(p=0.398)$ (Table 5). The other factors associated with higher NRM were age at allo-SCT (HR 1.41, $95 \%$ CI 1.24-1.59; $p<10^{-5}$ ); active disease (HR 1.35, $95 \%$ CI 1.14-1.60; $p=0.001$ ), secondary AML (HR 1.32, $95 \%$ CI 1.13-1.54; $p=0.0004$ ) and high CMV risk (HR 1.35, 95 \% CI 1.11-1.65; $p=0.002$ ). Karnofsky performance status at allo-SCT above $80 \%$ was associated with reduced NRM (HR 0.55, $95 \%$ CI $0.43-0.70 ; p<10^{-5}$ ) (Table 5).

The main causes of NRM were infectious complications and GVHD (Table 4). Death from infection was reported in 21, 100, and 249 patients and represented $51.2,41.7$, and $36.1 \%$ of the causes of NRM in the HLA $8 / 10,9 / 10$, and $10 / 10$ groups, respectively. Death from GVHD occurred in 10, 80, and 202 patients, representing 24.4, 33.3, and $29.3 \%$ of the causes of NRM in the $8 / 10,9 / 10$, and $10 / 10$ groups, respectively. Death from organ toxicity was low and represented $<10 \%$ of the causes of NRM in the three groups, in particular death related to sinusoidal obstructive syndrome (SOS) concerned 0,8 , and 12 patients $(0,0.4$, and $1.7 \%$ of causes of NRM) in the HLA $8 / 10,9 / 10$, and $10 / 10$ groups, respectively.

\section{Relapse}

Cumulative RI at 2 years was $30.4 \%$ (95 \% CI 28.8 32.1). In univariate analysis, RI was $24.2 \%$ (95 \% CI 16.4-32.9), $32.5 \%$ (95 \% CI 28.9-36.3), and $30.1 \%$ (95\% CI 28.2-32.1) in the HLA 8/10, 9/10, and 10/10 URD groups, respectively $(p=0.152)$ (Table 3$)$. Recurrence of original disease represented the first cause of death in the three groups of patients (Table 4). When analyzed according to disease status, in univariate analysis, RI was different between the three HLA typing groups for patients transplanted in CR1: $17.7 \%$ (95\% CI $8.1-30.2$ ) in the $8 / 10 \mathrm{mM}$-URD versus $31.6 \%$ (95\% CI $26.3-36.2)$ in the $9 / 10$ and $24.8 \%$ (95 \% CI 22.4-27.3) in the 10/10 URD group $(p=0.01)$ (Table 3 and Fig. $2 \mathrm{~b}$ ). Relapse incidence was similar between the three groups in more advanced diseases (Table 3 and Fig. 3b). In multivariate analysis, in comparison to 10/10 M-URD, the use of a $9 / 10 \mathrm{mM}$-URD was associated with an increased risk of relapse (HR 1.18, 95 \% CI 1.01-1.38; $p=0.038)$ and there was a trend for reduced risk of relapse with the use of an 8/10 mM-URD (HR 0.67, $95 \%$ CI $0.43-1.02 ; p=0.064$ ) (Table 5). Other factors associated with higher risk of relapse were advanced disease ( $\geq$ CR2) (HR 1.50, $95 \%$ CI 1.24-1.82; $p=4.10^{-5}$ ); active disease at allo-SCT (HR 2.06, $95 \%$ CI 1.76-2.42; $p<10^{-5}$ ) and the use of low-dose TBI-based RIC (HR $1.26,95 \%$ CI 1.07-1.48; $p=0.005)$. Shorter interval from diagnosis to allo-SCT was associated with reduced RI (HR 0.96, 95 \% CI 0.93-0.99; $p=0.007$ ) (Table 5). Of note, the use of in vivo $\mathrm{T}$ cell depletion had no impact on RI in both univariate and multivariate analyses (Tables 3 and 5).

\section{Leukemia-free survival}

Overall LFS at 2 years was $43.3 \%$ (95 \% CI 41.5-45.2). In univariate analysis, overall 2-year LFS was significantly higher in HLA 10/10 M-URD group (45.6\%, $95 \%$ CI 43.5-47.7) in comparison to mM-URD groups $(35.8 \%, 95 \%$ CI 32-39.7 in HLA $9 / 10$ and $40.3 \%, 95 \%$ CI 30.650 in HLA $8 / 10$ mM-URD groups) $(p=0.0001)$ (Table 3). Improved LFS with HLA 10/10 M-URD versus 
Table 5 Multivariate analysis

\begin{tabular}{|c|c|c|c|c|c|c|c|c|c|c|c|c|}
\hline & \multicolumn{2}{|l|}{ Relapse } & \multicolumn{2}{|l|}{ NRM } & \multicolumn{2}{|c|}{ Acute GVHD } & \multicolumn{2}{|c|}{ Chronic GVHD } & \multicolumn{2}{|l|}{ LFS } & \multicolumn{2}{|l|}{ OS } \\
\hline & $p$ value & $\mathrm{HR}(95 \% \mathrm{Cl})$ & $p$ value & HR $(95 \% \mathrm{Cl})$ & $p$ value & OR $(95 \% \mathrm{Cl})$ & $p$ value & HR $(95 \% \mathrm{Cl})$ & $p$ value & HR $(95 \% \mathrm{Cl})$ & $p$ value & $\mathrm{HR}(95 \% \mathrm{Cl})$ \\
\hline HLA 10/10 (ref) & & 1.00 & & 1.00 & & 1.00 & & 1.00 & & 1.00 & & 1.00 \\
\hline HLA 9/10 versus $10 / 10$ & 0.038 & $1.18(1.01-1.38)$ & 0.001 & $1.34(1.13-1.58)$ & 0.0001 & $1.47(1.21-1.79)$ & 0.418 & $1.07(0.91-1.26)$ & 0.0001 & $1.25(1.11-1.40)$ & 0.0001 & $1.27(1.13-1.44)$ \\
\hline HLA $8 / 10$ versus $9 / 10$ & 0.064 & $0.67(0.43-1.02)$ & 0.398 & $1.17(0.81-1.68)$ & 0.952 & $1.01(0.63-1.62)$ & 0.145 & $1.31(0.91-1.88)$ & 0.432 & $0.90(0.68-1.18)$ & 0.557 & $0.92(0.69-1.22)$ \\
\hline Age at SCT (10 years) & 0.701 & $1.02(0.91-1.15)$ & $<10^{-5}$ & $1.41(1.24-1.59)$ & 0.465 & $1.05(0.91-1.22)$ & 0.501 & $1.04(0.93-1.17)$ & 0.0001 & $1.18(1.09-1.29)$ & $<10^{-5}$ & $1.25(1.14-1.37)$ \\
\hline Interval diag. to $\mathrm{SCT}^{\mathrm{a}}$ & 0.007 & $0.96(0.93-0.99)$ & 0.636 & $1.01(0.98-1.03)$ & 0.306 & $0.98(0.95-1.02)$ & 0.833 & $1.00(0.97-1.02)$ & 0.108 & $0.98(0.96-1.00)$ & 0.122 & $0.98(0.96-1.00)$ \\
\hline \multicolumn{13}{|l|}{ Disease status at SCT } \\
\hline CR1 (ref) & & 1.00 & & 1.00 & & 1.00 & & 1.00 & & 1.00 & & 1.00 \\
\hline CR2 versus $C R 1$ & $4.10^{-5}$ & $1.50(1.24-1.82)$ & 0.713 & $1.04(0.85-1.28)$ & 0.728 & $1.04(0.82-1.32)$ & 0.558 & $1.06(0.88-1.28)$ & 0.002 & $1.25(1.09-1.44)$ & 0.016 & $1.20(1.03-1.39)$ \\
\hline Act.dis. versus CR1 & $<10^{-5}$ & $2.06(1.76-2.42)$ & 0.001 & $1.35(1.14-1.60)$ & 0.004 & $1.34(1.1-1.63)$ & 0.019 & $1.22(1.03-1.45)$ & $<10^{-5}$ & $1.69(1.51-1.90)$ & $<10^{-5}$ & $1.63(1.44-1.84)$ \\
\hline Secondary AML & 0.699 & $0.97(0.83-1.13)$ & 0.0004 & $1.32(1.13-1.54)$ & 0.418 & $1.08(0.90-1.30)$ & 0.196 & $1.11(0.95-1.29)$ & 0.029 & $1.13(1.01-1.26)$ & 0.021 & $1.14(1.02-1.28)$ \\
\hline Karnofsky $\geq 80 \%$ & 0.149 & $0.83(0.64-1.07)$ & $<10^{-5}$ & $0.55(0.43-0.70)$ & 0.838 & $0.97(0.70-1.33)$ & 0.318 & $0.86(0.64-1.16)$ & $10^{-5}$ & $0.68(0.57-0.81)$ & $<10^{-5}$ & $0.63(0.58-0.76)$ \\
\hline TBI & 0.005 & $1.26(1.07-1.48)$ & 0.767 & $1.03(0.85-1.24)$ & 0.088 & $0.83(0.67-1.03)$ & 0.610 & $1.04(0.88-1.24)$ & 0.019 & $1.16(1.02-1.30)$ & 0.022 & $1.16(1.02-1.32)$ \\
\hline In vivo T cell depletion & 0.483 & $1.07(0.89-1.27)$ & 0.253 & $0.90(0.74-1.08)$ & $<10^{-5}$ & $0.61(0.49-0.75)$ & 0.0001 & $0.72(0.61-0.85)$ & 0.790 & $0.98(0.86-1.12)$ & 0.72 & $0.98(0.85-1.12)$ \\
\hline Female $\mathrm{D}$ to male $\mathrm{R}$ & 0.112 & $0.84(0.68-1.04)$ & 0.172 & $1.15(0.94-1.42)$ & 0.063 & $1.26(0.99-1.61)$ & 0.078 & $1.19(0.98-1.45)$ & 0.846 & $0.99(0.85-1.14)$ & 0.896 & $1.01(0.87-1.18)$ \\
\hline High CMV risk (R+/D-) & 0.665 & $1.04(0.87-1.24)$ & 0.002 & $1.35(1.11-1.65)$ & 0.028 & $1.28(1.03-1.60)$ & 0.814 & $0.98(0.82-1.17)$ & 0.019 & $1.17(1.03-1.33)$ & 0.001 & $1.25(1.09-1.43)$ \\
\hline
\end{tabular}

Act.dis. active disease, $C R$ complete remission, $D$ donor, $D$ - donor, CMV serology, GVHD graft-versus-host-disease, LFS leukemia-free survival, NRM non relapse mortality, OS overall survival, $P B$ Peripheral blood, Ref reference, $R$ recipient, $R+$ positive recipient, $C M V$ serology, SCT allogeneic stem cell transplantation, $T B I$ total body irradiation

${ }^{a}$ Analyzed per 6-month interval 


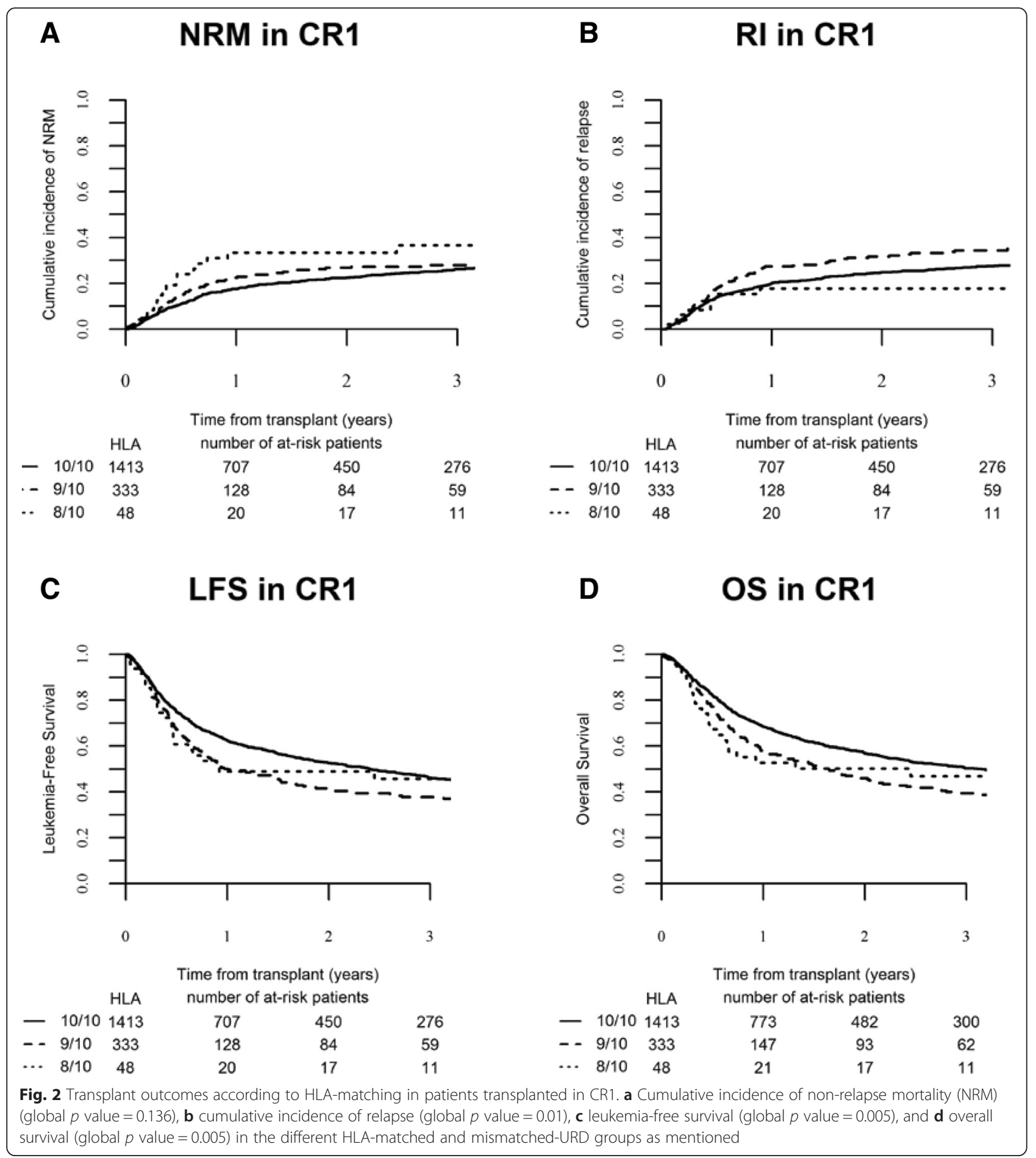

9/10 and 8/10 mM-URD groups was observed in patients transplanted in CR1 (52.6\%, 95 \% CI 49.7-55.5 versus $41.6 \%, 95 \% \mathrm{CI} 35.7-47.5$ and $49 \%$, $95 \% \mathrm{CI}$ 34.3-63.7, respectively, $p=0.005$ ) but not in patients transplanted in advanced stage diseases $(\geq C R 2$ and active disease) (Table 3, Figs. $2 \mathrm{c}$ and $3 \mathrm{c}$ ). In multivariate analysis, the use of a 9/10 mM-URD was associated with reduced LFS in comparison to HLA 10/10 M-URD (HR $1.25,95 \%$ CI 1.11-1.40; $p=0.0001$ ), while there was no difference between $9 / 10$ and $8 / 10$ mM-URD $(p=0.432)$ (Table 5). The other factors associated with shorter LFS were age at SCT (HR 1.18, $95 \%$ CI 1.09-1.29; $p=$ 0.0001 ); disease status $\geq$ CR2 at SCT (HR 1.25, $95 \%$ CI $1.09-1.44 ; p=0.002)$; active disease at SCT (HR 1.69, 


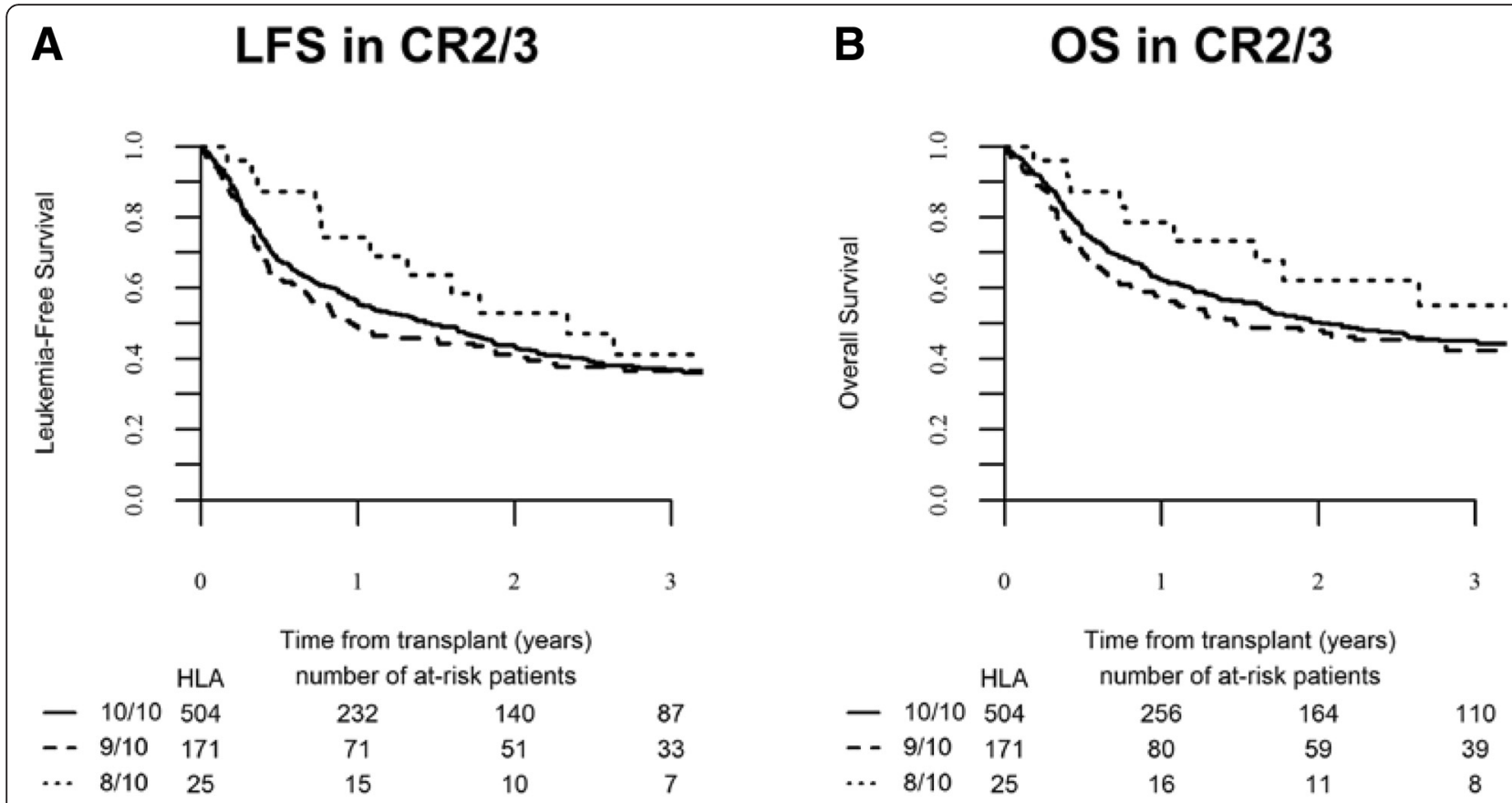

C LFS in active disease

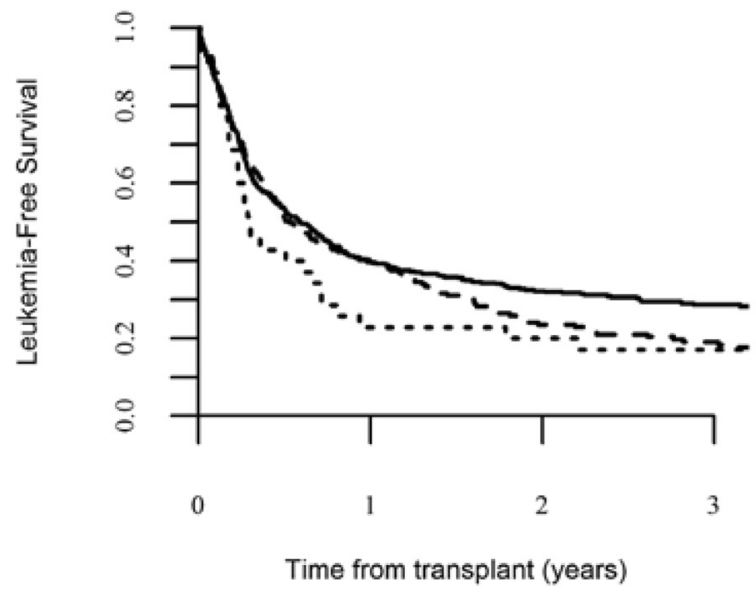

D OS in active disease

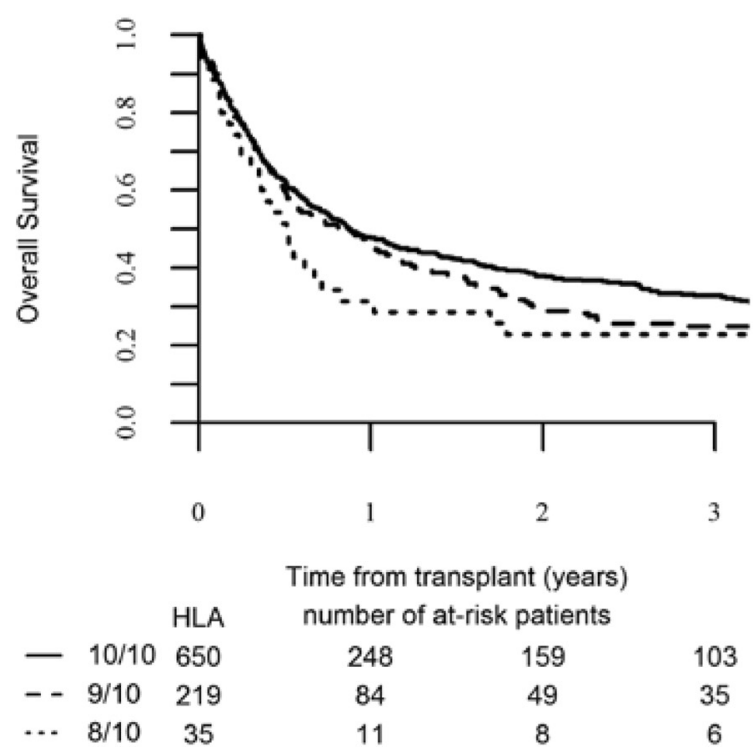

Fig 3 Transplant outcomes according to HLA-matching in patients transplanted with advanced diseases. a Leukemia-free survival (global $p$ value $=0.290$ ) and $\mathbf{b}$ overall survival (global $p$ value $=0.253$ ) of patients transplanted in CR2 and CR3 in the different HLA-matched and mismatched-URD groups as mentioned. $\mathbf{c}$ Leukemia-free survival (global $p$ value $=0.107$ ) and $\mathbf{d}$ overall survival ( $\mathrm{global} p$ value $=0.139$ ) of patients transplanted with active disease in the different HLA-matched and mismatched-URD groups as mentioned

$95 \%$ CI 1.51-1.90; $p<10^{-5}$ ); secondary AML (HR 1.13, $95 \%$ CI 1.01-1.26; $p=0.029$ ); use of low-dose TBI-based RIC (HR 1.16, $95 \%$ CI 1.02-1.30; $p=0.019$ ); and high CMV risk (seropositive recipient and seronegative donor) (HR 1.17, 95 \% CI 1.03-1.33; $p=0.019$ ). Karnofsky performance status at allo-SCT above $80 \%$ was associated with improved LFS (HR 0.68, 95 \% CI 0.57 $0.81 ; p=10^{-5}$ ) (Table 5). 


\section{Overall survival}

Overall survival at 2 years was $48.4 \%$ (95 \% CI 46.5-50.3). In univariate analysis, overall 2-year OS was significantly higher in HLA 10/10 M-URD group (50.6 \%, 95 \% CI 48.5-52.8) in comparison to mM-URD groups (41.3\%, $95 \%$ CI 37.3-45.3 in HLA $9 / 10$ and $43.5 \%$, $95 \%$ CI $33.6-53.3$ in HLA $8 / 10$ mM-URD groups) $(p=0.0001)$ (Table 3). Improved OS with HLA 10/10 M-URD versus 9/10 and 8/10 mM-URD groups was observed in patients transplanted in CR1 (56.7 \%, 95 \% CI 53.8-59.6 versus $46.1 \%, 95 \%$ CI 40.1-52.2 and 50.2 \%, 95 \% CI 35.2-65.1, respectively, $p=0.005)$ but not in patients transplanted in $\geq$ CR2 or with active disease (Table 3, Figs. $2 \mathrm{~d}$ and $3 \mathrm{~d}$ ). The use of in vivo $\mathrm{T}$ cell depletion had no impact on OS $(p=0.45)$ (Table 3). In multivariate analysis, the use of a 9/10 mM-URD was associated with reduced OS in comparison to HLA 10/10 M-URD (HR 1.27; $95 \%$ CI, $1.13-1.44 ; p=0.0001$ ), while there was no difference between $9 / 10$ and $8 / 10 \mathrm{mM}$-URD $(p=0.557)$ (Table 5). The other factors associated with shorter OS were age at SCT (HR 1.25; $95 \%$ CI, 1.14-1.37; $p<10^{-5}$ ), disease status $\geq$ CR2 at SCT (HR 1.20; $95 \%$ CI, 1.03-1.39; $p=0.016)$, active disease at SCT (HR 1.63; $95 \%$ CI, 1.44-1.84; $p<10^{-5}$ ), secondary AML (HR 1.14; $95 \% \mathrm{CI}, 1.02-$ 1.28; $p=0.021$ ), use of low-dose TBI-based RIC (HR 1.16; $95 \% \mathrm{CI}, 1.02-1.32 ; p=0.022$ ), and high CMV risk (seropositive recipient and seronegative donor) (HR 1.25; 95 \% CI, 1.09-1.43; $p=0.002$ ). Karnofsky performance status at SCT above $80 \%$ was associated with prolonged OS (HR 0.63; $95 \% \mathrm{CI}, 0.58-0.76 ; p<10^{-5}$ ) (Table 5).

\section{Discussion}

Unrelated donors represent the most frequent stem cell source for allo-SCT in Europe and are used in more than $50 \%$ of RIC allo-SCT for AML patients [15]. In the absence of HLA-matched URD, a significant proportion of patients is transplanted with a $9 / 10$ and to a less extends, with an $8 / 10 \mathrm{mM}-\mathrm{URD}$. Although outcomes of RIC allo-SCT with HLA 10/10 or 8/8 MUD have been reported as comparable to transplants performed with a matched related donor [6, 18-20], the outcomes of MURD versus mM-URD for older adults with AML have been poorly explored. This large, multicenter, registry study showed superior outcome using HLA-matched (10/10) donor compared to mM-URD (9/10 or $8 / 10)$ allo-SCT for AML in patients above the age of 50 years. Patients receiving $\mathrm{mM}$-URD had significantly higher incidence of acute GVHD (both grades II-IV and II-IV) and NRM. A larger series of patients transplanted with RIC or MAC regimens for AML reported by the CIBMTR similarly showed increased risk of NRM with 7/8 mMURD $(n=406)$ compared to $8 / 8$ M-URD $(n=1193)$ or
MRD $(n=624)$ due to increased incidence of acute GVHD in M-URD versus MRD [29].

We did not observe any impact of HLA matching on the overall incidence of chronic GVHD. However, in univariate analysis, the use of an $8 / 10 \mathrm{mM}$-URD was associated with increased risk of overall and extensive chronic GVHD particularly for patients transplanted in advanced phase disease. In our study, the other factors associated with a higher risk of both acute and chronic GVHD were active disease at transplantation and the absence of in vivo $\mathrm{T}$ cell depletion. In addition, patient age above 60 years and Karnofsky performance status below $80 \%$ had a negative impact on NRM. Thus, the choice of a mM-URD for elderly patients transplanted with RIC-allo SCT requires the use of ATG and should take into consideration the higher risk of GVHD and NRM, in particular for patients above 60 years, not in CR and/ or with an decreased performance status at allo-SCT.

In contrast to the reduced risk of relapse observed in the CIBMTR study with the use of $7 / 8 \mathrm{mM}$-URD in comparison to 8/8 MRD and M-URD [29], the use of a 9/10 mM-URD in our study was associated with a higher risk of relapse in comparison to 10/10 M-URD in multivariate analysis. There was, however, a trend for reduced relapse incidence with $8 / 10$ in comparison to 9/10 mM-URD (HR 0.67, 95 \% CI 0.43-1.02; $p=0.064$ ). These differences might be explained by higher proportions of patients transplanted with active disease in the mM-MUD groups and by more intensive and prolonged immunosuppression administered to patients receiving mM-URD allo-SCT in order to control acute GVHD. This might have affected the development of the graft-versus-leukemia (GVL) effect, otherwise expected at higher level with mismatched donor $\mathrm{T}$ cells. Consistent with this hypothesis is the absence of increased chronic GVHD in the 9/10 mM-URD versus the 10/10 M-URD groups, while higher incidence of extensive chronic GVHD in the 8/10 mM-URD was associated with a trend towards reduced relapse incidence, in particular observed in patients transplanted in CR1. Another factor associated with increased risk of relapse, leading to reduced LFS and OS, was the use of a lowdose TBI-based RIC (truly non-ablative) regimen, suggesting that increasing the intensity of the conditioning might help for the control of the disease until the GVL response takes place [30].

As expected, disease status at SCT was another important factor impacting RI, LFS, and OS. In our study in older adults with AML transplanted in CR1, the 2year OS was comparable to prior reports using RIC and MRD [11] and to younger AML patients transplanted with MAC regimens and MRD or M-URD allo-SCT [31]. Although LFS and OS were reduced with $\mathrm{mM}$ URD in patients transplanted in CR, 2-year OS for 
patients transplanted in CR1 or in $>$ CR1 were between 46 and $50 \%$ with a $9 / 10$ or $8 / 10$ mM-URD transplantation, comparable to results of RIC for AML with MRD and M-URD $[3,4,6]$, suggesting that $\mathrm{mM-URD}$ remains a valid option for AML above 50 years old, in particular for those transplanted in $>$ CR1.

The feasibility of haplo-identical SCT performed with $\mathrm{T}$ replete stem cell grafts and in vivo $\mathrm{T}$ cell depletion based either on ATG [32] or post-transplant cyclophosphamide [33] has been demonstrated in the past 10 years. Comparisons of haplo-identical SCT using the Chinese approach combining $\mathrm{T}$ replete G-CSF mobilized bone marrow stem cell graft, a myeloablative conditioning regimen with ATG, to matched related and unrelated allo-SCT for acute leukemias have shown equivalent OS with reduced risk of relapse in high-risk leukemias in the haplo-identical groups [34, 35]. Using this approach, the Beijing's group recently reported similar outcomes in fit patients transplanted above 50 years of age in comparison to younger patients [36]. In the setting of posttransplant cyclophosphamide, Blaise et al. reported in patients older than 60 years inferior outcomes of RIC allo-SCT performed with HLA 10/10 and 9/10 URD compared to those transplanted with MRD or haploidentical donors because of higher NRM related to higher incidence of acute and chronic GVHD [37]. Comparisons of haplo-identical SCT at the era of posttransplant cyclophosphamide to URD have shown similar LFS and OS but reduced NRM and chronic GVHD with T replete haplo-SCT [38-41]. From 2012 onward, there has been increasing numbers of transplants performed from related haplo-identical donor, which is likely mainly due to increased use of haplo-identical donors with the post-transplant cyclophosphamide strategy. In AML patients undergoing allo-SCT without an HLA-matched (related or unrelated) donor, the decision to use one alternative graft source over another is complex. Published data support any one of the three alternative donor allo-SCT options (i.e., mM-URD, CBT, related haplo-identical) currently available for patients without a matched donor. Our current study support this notion as results of mM-URD in AML patients with age above 50 years transplanted in CR1 were inferior to matched URD and therefore other alternative like Haplo-SCT and CBT may be considered.

\section{Conclusions}

We recognize that this study has limitations mainly due to the fact that it is a retrospective and registry-based study. Despite these limitations, these results suggest that HLA 10/10 M-URD is the preferable option for AML patients older than 50 years undergoing allogeneic transplantation following RIC preparative regimen. The use of a $9 / 10$ or $8 / 10 \mathrm{mM}$-URD could be an alternative therapeutic option for patients not having a matched donor. Prospective randomized studies comparing $\mathrm{mM}-$ URD to other alternative donors, in particular haploidentical SCT, are warranted.

\section{Additional file}

Additional file 1: Table S1. List of institutions reporting patients' data for the study. (DOCX $29 \mathrm{~kb}$ )

\begin{abstract}
Abbreviations
aGVHD, acute graft-versus-host disease; Allo-SCT, allogeneic hematopoietic stem cell transplantation; AML, acute myeloid leukemia; ATG, anti-thymocyte globulin; BM, bone marrow; CGVHD, chronic graft-versus-host-disease; CMV, cytomegalovirus; CR, complete remission; LFS, leukemia-free survival; MAC, myeloablative conditioning; mM-URD, mismatched unrelated donor (); MRD, matched related donor; M-URD, matched unrelated donor; NRM, non relapse mortality (); OS, overall survival; PB, peripheral blood; RI, relapse incidence, $\mathrm{RIC}$, reduced intensity conditioning; SOS, sinusoidal obstructive syndrome (); $\mathrm{TBI}$, total body irradiation
\end{abstract}

\section{Acknowledgements}

Not applicable.

Funding

Not applicable.

\section{Availability of data and materials}

$M L, E P, M M$, and AN had full access to all the data in the study (available upon data specific request).

MTR, BNS, MM, and AN had final responsibility for the decision to submit for publication.

\section{Authors' contributions}

MTR, BNS, ML, MM, and AN designed the research and/or analyzed the data. $\mathrm{DN}, \mathrm{AG}, \mathrm{GE}, \mathrm{MB}, \mathrm{AR}, \mathrm{JF}, \mathrm{NK}, \mathrm{CC}, \mathrm{RS}, \mathrm{MH}$, and PJ provided clinical data. MTR, BNS, ML, MM, and AN wrote the manuscript. A complete list of contributors, as well as members of the European Blood and Marrow Transplantation Group appears on the additional file. All authors read and approved the final manuscript.

\section{Competing interests}

The authors declare that they have no competing interests.

\section{Consent for publication}

Not applicable.

\section{Ethics approval and consent to participate}

The study protocol was approved by the institutional review board at each site and complied with country-specific regulatory requirements. The study was conducted in accordance with the Declaration of Helsinki and Good Clinical Practice guidelines. Patients provide informed consent authorizing the use of their personal information for research purposes.

\section{Author details}

'Department of Hematology, Hôpital Brabois, CHRU Nancy,

Vandœuvre-lès-Nancy, France. ${ }^{2}$ CNRS UMR 7365, IMoPA, Nancy, France. ${ }^{3}$ Université de Lorraine, Nancy, France. ${ }^{4}$ Acute Leukemia Working Party of EBMT, Paris, France. ${ }^{5}$ Vanderbilt University Medical Center, Nashville, TN, USA. ${ }^{6}$ EBMT Paris study office/CEREST-TC, Paris, France. ${ }^{7}$ Department of Haematology, Saint Antoine Hospital, Paris, France. ${ }^{8}$ INSERM UMR 938, Paris, France. ${ }^{9}$ Université Pierre et Marie Curie, Paris, France. ${ }^{10}$ Division Hematology, Oncology and Hemostasiology, University Hospital Leipzig, Leipzig, Germany.

${ }^{11}$ Department of Haematology, Hemostasis, Oncology and Stem Cell Transplantation, Hannover Medical School, Hannover, Germany. ${ }^{12}$ Deutsche KlinikfürDiagnostik, KMT Zentrum, Wiesbaden, Germany. ${ }^{13}$ Medizinische Klinik und Poliklinik I, Universitätsklinikum Carl Gustav Carus der TU Dresden, Dresden, Germany. ${ }^{14}$ Department of Medicine, Hematology, Oncology, 
University of Freiburg, Freiburg, Germany. ${ }^{15}$ MedizinischeKlinik m. S. Hämatologie/Onkologie, Campus Virchow Klinikum, Charité Universitätsmedizin Berlin, Berlin, Germany. ${ }^{16} \mathrm{Centre}$ for Clinical Haematology, Queen Elizabeth Hospital, Birmingham, UK. ${ }^{17}$ Department of Stem cell Transplantation, University Hospital Eppendorf, Hamburg, Germany. ${ }^{18}$ Department of Medicine, University of Cologne, Cologne, Germany. ${ }^{19}$ Department of Hematology/Oncology, Charles University Hospital, Pilsen, Czech Republic. ${ }^{20}$ Hematology Division, Chaim Sheba Medical Center, Tel Hashomer, Ramat Gan, Israel.

\section{Received: 6 June 2016 Accepted: 27 July 2016} Published online: 03 August 2016

\section{References}

1. Slavin S, Nagler A, Naparstek E, Kapelushnik Y, Aker M, Cividalli G, et al. Nonmyeloablative stem cell transplantation and cell therapy as an alternative to conventional bone marrow transplantation with lethal cytoreduction for the treatment of malignant and nonmalignant hematologic diseases. Blood. 1998;91(3):756-63.

2. McSweeney PA, Niederwieser D, Shizuru JA, Sandmaier BM, Molina AJ, Maloney DG, et al. Hematopoietic cell transplantation in older patients with hematologic malignancies: replacing high-dose cytotoxic therapy with graft-versus-tumor effects. Blood. 2001;97(11):3390-400

3. Shimoni A, Kroger N, Zabelina T, Ayuk F, Hardan I, Yeshurun M, et al. Hematopoietic stem-cell transplantation from unrelated donors in elderly patients (age $>55$ years) with hematologic malignancies: older age is no longer a contraindication when using reduced intensity conditioning. Leukemia. 2005;19(1):7-12.

4. Valcarcel D, Martino R, Caballero D, Martin J, Ferra C, Nieto JB, et al Sustained remissions of high-risk acute myeloid leukemia and myelodysplastic syndrome after reduced-intensity conditioning allogeneic hematopoietic transplantation: chronic graft-versus-host disease is the strongest factor improving survival. J Clin Oncol. 2008;26(4):577-84.

5. Ringden O, Labopin M, Ehninger G, Niederwieser D, Olsson R, Basara N, et al. Reduced intensity conditioning compared with myeloablative conditioning using unrelated donor transplants in patients with acute myeloid leukemia. J Clin Oncol. 2009:27(27):4570-7.

6. Gyurkocza B, Storb R, Storer BE, Chauncey TR, Lange T, Shizuru JA, et al. Nonmyeloablative allogeneic hematopoietic cell transplantation in patients with acute myeloid leukemia. J Clin Oncol. 2010;28(17):2859-67.

7. Chevallier P, Szydlo RM, Blaise D, Tabrizi R, Michallet M, Uzunov M, et al. Reduced-intensity conditioning before allogeneic hematopoietic stem cell transplantation in patients over 60 years: a report from the SFGM-TC. Biol Blood Marrow Transplant. 2012;18(2):289-94.

8. Sengsayadeth S, Savani BN, Blaise D, Malard F, Nagler A, Mohty M. Reduced intensity conditioning allogeneic hematopoietic cell transplantation for adult acute myeloid leukemia in complete remission-a review from the Acute Leukemia Working Party of the EBMT. Haematologica. 2015;100(7): 859-69.

9. Mohty $M$, de Lavallade $H$, Ladaique $P$, Faucher $C$, Vey $N$, Coso D, et al. The role of reduced intensity conditioning allogeneic stem cell transplantation in patients with acute myeloid leukemia: a donor vs no donor comparison. Leukemia. 2005;19(6):916-20.

10. Kurosawa S, Yamaguchi T, Uchida N, Miyawaki S, Usuki K, Watanabe M, et al. Comparison of allogeneic hematopoietic cell transplantation and chemotherapy in elderly patients with non-M3 acute myelogenous leukemia in first complete remission. Biol Blood Marrow Transplant. 2011; 17(3):401-11.

11. Russell NH, Kjeldsen L, Craddock C, Pagliuca A, Yin JA, Clark RE, et al. A comparative assessment of the curative potential of reduced intensity allografts in acute myeloid leukaemia. Leukemia. 2015;29(7):1478-84.

12. Aoudjhane M, Labopin M, Gorin NC, Shimoni A, Ruutu T, Kolb HJ, et al. Comparative outcome of reduced intensity and myeloablative conditioning regimen in HLA identical sibling allogeneic haematopoietic stem cell transplantation for patients older than 50 years of age with acute myeloblastic leukaemia: a retrospective survey from the Acute Leukemia Working Party (ALWP) of the European group for Blood and Marrow Transplantation (EBMT). Leukemia. 2005:19(12):2304-12.

13. Champlin R. Reduced intensity allogeneic hematopoietic transplantation is an established standard of care for treatment of older patients with acute myeloid leukemia. Best Pract Res Clin Haematol. 2013;26(3):297-300.
14. Hahn T, McCarthy Jr PL, Hassebroek A, Bredeson C, Gajewski JL, Hale GA, et al. Significant improvement in survival after allogeneic hematopoietic cell transplantation during a period of significantly increased use, older recipient age, and use of unrelated donors. J Clin Oncol. 2013;31(19):2437-49.

15. Passweg JR, Baldomero H, Bader P, Bonini C, Cesaro S, Dreger $P$, et al. Hematopoietic SCT in Europe 2013: recent trends in the use of alternative donors showing more haploidentical donors but fewer cord blood transplants. Bone Marrow Transplant. 2015;50(4):476-82.

16. Sierra J, Martino R, Sanchez B, Pinana JL, Valcarcel D, Brunet S. Hematopoietic transplantation from adult unrelated donors as treatment for acute myeloid leukemia. Bone Marrow Transplant. 2008;41(5):425-37.

17. Gooley TA, Chien JW, Pergam SA, Hingorani S, Sorror ML, Boeckh M, et al. Reduced mortality after allogeneic hematopoietic-cell transplantation. N Engl J Med. 2010;363(22):2091-101.

18. Huisman C, Meijer E, Petersen EJ, Lokhorst HM, Verdonck LF. Hematopoietic stem cell transplantation after reduced intensity conditioning in acute myelogenous leukemia patients older than 40 years. Biol Blood Marrow Transplant. 2008;14(2):181-6.

19. Schetelig J, Bornhauser M, Schmid C, Hertenstein B, Schwerdtfeger R, Martin $\mathrm{H}$, et al. Matched unrelated or matched sibling donors result in comparable survival after allogeneic stem-cell transplantation in elderly patients with acute myeloid leukemia: a report from the cooperative German Transplant Study Group. J Clin Oncol. 2008;26(32):5183-91.

20. Robin M, Porcher R, Ades L, Boissel N, Raffoux E, Xhaard A, et al. Matched unrelated or matched sibling donors result in comparable outcomes after non-myeloablative HSCT in patients with AML or MDS. Bone Marrow Transplant. 2013;48(10):1296-301.

21. Appelbaum FR, Gundacker H, Head DR, Slovak ML, Willman CL, Godwin JE, et al. Age and acute myeloid leukemia. Blood. 2006;107(9):3481-5.

22. Kantarjian H, O'Brien S, Cortes J, Giles F, Faderl S, Jabbour E, et al. Results of intensive chemotherapy in 998 patients age 65 years or older with acute myeloid leukemia or high-risk myelodysplastic syndrome: predictive prognostic models for outcome. Cancer. 2006;106(5):1090-8.

23. Shimoni A, Nagler A. Non-myeloablative hematopoietic stem cell transplantation (NST) in the treatment of human malignancies: from animal models to clinical practice. Cancer Treat Res. 2002:110:113-36.

24. Petersen SL. Alloreactivity as therapeutic principle in the treatment of hematologic malignancies. Studies of clinical and immunologic aspects of allogeneic hematopoietic cell transplantation with nonmyeloablative conditioning. Dan Med Bull. 2007;54(2):112-39.

25. Ho VT, Kim HT, Aldridge J, Liney D, Kao G, Armand P, et al. Use of matched unrelated donors compared with matched related donors is associated with lower relapse and superior progression-free survival after reduced-intensity conditioning hematopoietic stem cell transplantation. Biol Blood Marrow Transplant. 2011:17(8):1196-204.

26. Bacigalupo A, Ballen K, Rizzo D, Giralt S, Lazarus H, Ho V, et al. Defining the intensity of conditioning regimens: working definitions. Biol Blood Marrow Transplant. 2009;15(12):1628-33.

27. Przepiorka D, Weisdorf D, Martin P, Klingemann HG, Beatty P, Hows J, et al. 1994 Consensus Conference on Acute GVHD Grading. Bone Marrow Transplant. 1995:15(6):825-8.

28. Shulman HM, Sullivan KM, Weiden PL, McDonald GB, Striker GE, Sale GE, et al. Chronic graft-versus-host syndrome in man. A long-term clinicopathologic study of 20 Seattle patients. Am J Med. 1980;69(2):204-17.

29. Saber W, Opie S, Rizzo JD, Zhang MJ, Horowitz MM, Schriber J. Outcomes after matched unrelated donor versus identical sibling hematopoietic cell transplantation in adults with acute myelogenous leukemia. Blood. 2012; 119(17):3908-16.

30. Luger SM, Ringden O, Zhang MJ, Perez WS, Bishop MR, Bornhauser M, et al. Similar outcomes using myeloablative vs reduced-intensity allogeneic transplant preparative regimens for AML or MDS. Bone Marrow Transplant. 2012:47(2):203-11.

31. Yakoub-Agha I, Mesnil F, Kuentz M, Boiron JM, Ifrah N, Milpied N, et al. Allogeneic marrow stem-cell transplantation from human leukocyte antigen-identical siblings versus human leukocyte antigen-allelic-matched unrelated donors (10/10) in patients with standard-risk hematologic malignancy: a prospective study from the French Society of Bone Marrow Transplantation and Cell Therapy. J Clin Oncol. 2006;24(36):5695-702.

32. Huang XJ, Liu DH, Liu KY, Xu LP, Chen H, Han W, et al. Treatment of acute leukemia with unmanipulated HLA-mismatched/haploidentical blood and bone marrow transplantation. Biol Blood Marrow Transplant. 2009;15(2):257-65. 
33. Luznik L, O'Donnell PV, Symons HJ, Chen AR, Leffell MS, Zahurak M, et al. HLA-haploidentical bone marrow transplantation for hematologic malignancies using nonmyeloablative conditioning and high-dose, posttransplantation cyclophosphamide. Biol Blood Marrow Transplant. 2008; 14(6):641-50.

34. Yu S, Fan Q, Sun J, Fan Z, Zhang Y, Jiang Q, et al. Haploidentical transplantation without in vitro T-cell depletion results in outcomes equivalent to those of contemporaneous matched sibling and unrelated donor transplantation for acute leukemia. Medicine (Baltimore). 2016;95(11), e2973.

35. Luo Y, Xiao H, Lai X, Shi J, Tan Y, He J, et al. T-cell-replete haploidentical HSCT with low-dose anti-T-lymphocyte globulin compared with matched sibling HSCT and unrelated HSCT. Blood. 2014;124(17):2735-43.

36. Chen Y, Wang Y, Xu LP, Liu KY, Chen H, Chen YH, et al. Haploidentical stem cell transplantation in patients aged $50 \mathrm{yr}$ and older with leukemia: similar outcomes compared to younger adults. Clin Transplant. 2015;29(6):523-30.

37. Blaise D, Furst S, Crocchiolo R, El-Cheikh J, Granata A, Harbi S, et al. Haploidentical T cell-replete transplantation with post-transplantation cyclophosphamide for patients in or above the sixth decade of age compared with allogeneic hematopoietic stem cell transplantation from an human leukocyte antigen-matched related or unrelated donor. Biol Blood Marrow Transplant. 2016;22(1):119-24

38. Bashey A, Zhang X, Jackson K, Brown S, Ridgeway M, Solh M, et al. Comparison of outcomes of hematopoietic cell transplants from T-replete haploidentical donors using post-transplantation cyclophosphamide with 10 of 10 HLA-A, $-B_{1}-C_{1}-D R B 1$, and $-D Q B 1$ allele-matched unrelated donors and HLA-identical sibling donors: a multivariable analysis including Disease Risk Index. Biol Blood Marrow Transplant. 2016;22(1):125-33.

39. Raiola AM, Dominietto A, di Grazia C, Lamparelli T, Gualandi F, Ibatici A, et al. Unmanipulated haploidentical transplants compared with other alternative donors and matched sibling grafts. Biol Blood Marrow Transplant. 2014;20(10):1573-9.

40. Ciurea SO, Zhang MJ, Bacigalupo AA, Bashey A, Appelbaum FR, Aljitawi OS, et al. Haploidentical transplant with posttransplant cyclophosphamide vs matched unrelated donor transplant for acute myeloid leukemia. Blood. 2015;126(8):1033-40.

41. Kanate AS, Mussetti A, Kharfan-Dabaja MA, Ahn KW, DiGilio A, Beitinjaneh A et al. Reduced-intensity transplantation for lymphomas using haploidentical related donors vs HLA-matched unrelated donors. Blood. 2016;127(7):938-47.

\section{Submit your next manuscript to BioMed Central and we will help you at every step:}

- We accept pre-submission inquiries

- Our selector tool helps you to find the most relevant journal

- We provide round the clock customer support

- Convenient online submission

- Thorough peer review

- Inclusion in PubMed and all major indexing services

- Maximum visibility for your research

Submit your manuscript at www.biomedcentral.com/submit 